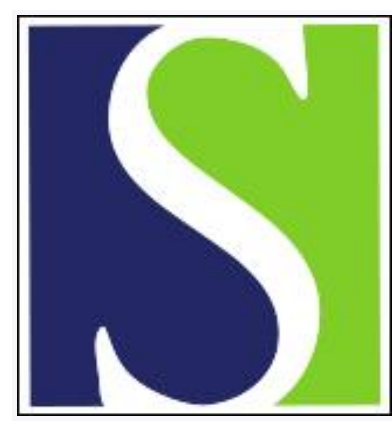

Scand J Work Environ Health 1978;4(1):1-18

https://doi.org/10.5271/sjweh.2726

Issue date: Mar 1978

Biological monitoring. Guest lecture given at the 26th Nordic symposium on industrial hygiene, Helsinki, October 1977.

by Zielhuis RL

Key terms: biological monitoring; guest lecture; industrial hygiene

This article in PubMed: www.ncbi.nlm.nih.gov/pubmed/644264 
Scand. j. work environ. \& health 4 (1978) 1-18

\title{
Biological monitoring
}

\section{Guest lecture given at the 26th Nordic Symposium on Industrial Hygiene, Helsinki, October 1977}

\author{
by R. L. ZIELHUIS, Ph.D., M.D. ${ }^{1}$
}

The organizing committee of the Symposium requested that I discuss the general aspects of biological monitoring for both occupational and public health. This subject allows me to emphasize the significance of occupational toxicology for public health toxicology. A few years ago I had the opportunity to speak on this topic in another guest lecture, the "BaaderVorlesung," before the Deutsche Gesellschaft für Arbeitsmedizin (26).

Epidemiologic studies in occupational toxicology produce data essential for the understanding and prediction of many potential health risks among the general population. Studies of heavy metals, chlorinated pesticides, carcinogenic agents are good examples. Public health toxicology uses the same methods and techniques and follows a similar approach. In fact occupational toxicology is the mother of public health toxicology. Occupational physicians and hygienists have much better opportunities to study exposure-response relationships than public health workers. This increase in opportunity also applies to biological monitoring. Therefore, if occupational health workers have better opportunities, then they must also use them. Data essential for the evaluation of public health risks cannot, at least without much difficulty, be gathered outside industry.

1 Coronel Laboratory, Faculty of Medicine, Iniversity of Amsterdam, Amsterdam, The Netherlands.

Reprint requests to: Dr. R. L. Zielhuis, Coronel Laboratory, Faculty of Medicine, University of Amsterdam, 1st Constantijn Huygensstraat 20, Amsterdam, The Netherlands.
One should not forget that an environmentally exposed woman or child is much more like an industrially exposed male worker than an experimentally exposed rat, mouse, or monkey, even though many expressions exist in everyday language which indicate a similarity between humans and animals: pig, snake, chicken, hawk, pigeon, etc.

\section{WHAT IS BIOLOGICAL MONITORING?}

In its original concept the word monitoring means "continuous measurement of a variable over time," and it often includes a check on the comparability of the registered signal with a present level of, e.g., barometric pressure, humidity, radioactivity. In occupational and environmental hygiene, there exists the concept of environmental monitoring, i.e., measurement of external exposure to agents in air, food, water. It measures concentrations, amounts, and intensities (either continuously or noncontinuously), as well as frequencies and durations of exposure.

In addition there is also biological monitoring, i.e., measurement of internal exposure through analysis of a biological specimen. This type of monitoring cannot usually be carried out continuously, but must be done either at one point in time or at subsequent points in time.

In April 1977 a workshop organized by the Commission of European Communities (CEC) - World Health Organization (WHO) and the U.S. Environmental Pro- 
tection Agency (EPA) presented the following definition for biological monitoring: "systematic collection of biological specimen for which analysis of pollutants is for immediate application;" environmental monitoring accordingly refers to "systematic collection of environmental samples, such as air, food, water for analysis of pollutant concentration" (6).

The original meaning of continuous measurement has been lost in both environmental and biological monitoring. In recent years the term biological surveillance has also been introduced for biological monitoring programs meant to be carried out once only.

Biological monitoring is on the upswing, both in occupational and environmental health, because of several reasons, i.e., (a) increased understanding of pharmacokinetics, (b) fast improvement in analytical techniques, and (c) the realization that biological monitoring may have great advantages over environmental monitoring.

If people become enthusiastic about a new concept, they start using it for everything. This has happened for "ergonomy," which sometimes is said to cover almost everything connected with occupational health, and for "ecology," which is said to cover everything connected with environmental impact, and also for biological monitoring, which is said to cover almost everything connected with the examination of workers or population groups exposed to toxic agents. However, if a concept covers everything, then it does not say anything at all. One simply has old wine in new bottles.

Let us therefore reserve the term biological monitoring as a specified concept, i.e., as the measurement or estimation of exposure. Biological monitoring is primarily connected with the pharmacokinetics of toxic agents, and not with health effects (pharmacodynamics).

Exposure tests are a part of occupational health activities. These are the real tools of biological monitoring. Either the primary agent itself or its metabolites in the biological specimen are measured. There are a few exceptions: if the agents induce reasonably specific biochemical effects, the presence of which is highly related to exposure, then such effects may also be in- cluded in biological monitoring programs. I will mention only a few: cholinesterase inhibition in exposure to organophosphate pesticides, free erythrocyte protoporphyrin/zinc protoporphyrin in red blood cells and aminolevulinic acid in urine in exposure to lead, and methemoglobin in exposure to aromatic amino compounds.

Biological monitoring must clearly be distinguished from the evaluation of health effects, e.g., depression of leukocytes, changes in enzyme patterns or lung function, screening for bladder carcinomas. This is health screening aimed at detecting individuals with impending or already evident health effects, while biological monitoring primarily aims at determining exposure of groups of subjects, and of individual members of such a group. Many health effects are not specific for the agent causing the effect, whereas biological monitoring usually deals with parameters highly specific for the agent under consideration. As an example of the wrong use of the word, I can mention the workshop on occupational monitoring for genetic hazards (13), in which almost all the papers discussed mutagenicity studies and chromosome analysis.

Exactly the same approach may be followed in estimating exposure in, e.g., fish, seals, urban pigeons, or plants. The same approach must be followed, often using similar analytical techniques. There is need for close cooperation between physicians and hygienists dealing with biological monitoring in man and chemists and biologists dealing with other organisms. However, in regard to health effects, there is very little similarity in approach; counting the number of dead birds or fish or studying the discoloration of leaves has very little to do with human health effect studies.

\section{OMITTED ASPECTS OF BIOLOGICAL MONITORING}

Biological monitoring covers a very broad range of applications. I will limit myself to exposed human population groups during their normal life, groups such as those encountered in industry or within the general environment. There is an expanding application of the biological moni- 
toring of tissues taken from surgery, or placenta or umbilical cord, or from autopsy, but this form will be left out of my discussion.

In biological monitoring analytical techniques are of paramount importance. In fact the development of analytical methods is essential for enlarging the scope of biological monitoring. Interlaboratory comparison programs are being carried out more and more, although it is the experience of our laboratory that it is still difficult to start such programs. This highly important aspect of biological monitoring will not be discussed either.

General reviews covering one or several groups of agents have been published. In 1976 the Directorate Health Protection of the CEC, Section Occupational Health, started a large literature review program; eight institutes are preparing reviews on groups of agents relevant to occupational health. This work is in progress now. Lauwerys from Brussels is the coordinator; meetings have already been held for a discussion of reviews on a number of metals, and on benzene, toluene, xylene and styrene. The CEC intends to publish the whole collection as soon as possible. It is planned that in 1978 the first reviews will appear on the market. The Coronel Laboratory submitted a review on chlorinated hydrocarbons used as solvents and anaesthetics (16).

If one examines the existing literature critically, one will see that much of it does not give reliable answers to the following leading questions: Is it possible to predict from biological monitoring data the occupational exposure intensity for groups, let alone for individuals, and what is the level of confidence of the data provided? Too often literature only gives data on average external exposure levels and average levels of agents or metabolites in biological specimens; hardly no data are available on individual pharmacokinetics. Much too often the external exposure data are highly deficient. Moreover, the very important data on human volunteer studies usually refer to short-term exposures. Literature reviews are important to present the state of the art of biological monitoring, but it should not be forgotten that the state of the art of biological monitoring is still rather low.
In this communication only general principles of biological monitoring are discussed, and most of the examples are taken from the limited area that we are working on ourselves in Amsterdam. The examples may be illustrative of the great possibilities on one hand; but also of the large gaps in knowledge on the other. However, showing both the positive and the negative side of the current situation may help to tackle the problems before us, both in occupational and in public health.

\section{LEVELS OF ORGANIZATION}

There are four levels in the organization of health care and interaction with the environment: the micro-, meso-, macroand megalevels.

At the microlevel are the individual subjects and their families. This is the level of individual curative and preventive medicine. Biological monitoring may be applied in the evaluation of drug metabolism during therapy, but also in the measurement of alcohol in exhaled air or blood, as required by law for traffic safety.

At the mesolevel are groups in organized social systems: schools, industries, offices. Preventive and, in some countries also, curative health care is provided by occupational health services. It is at this level that occupationally exposed workers are monitored biologically.

At the macrolevel are groups in much less closely organized and supervised social systems: the general public at large, in a town, a region, or a nation. At this level biological monitoring is a tool for public health studies.

At the megalevel are such international organiations as WHO and UNEP. They have dealt with studies on levels of lead, cadmium, mercury in blood and urine from various parts of the world and with studies on the distribution of levels of DDT and its metabolites in adipose tissue in many population groups.

In this paper I concern myself mainly with the meso- and macrolevel: occupational and public health. However, it should not be forgotten that human beings always function in all four levels at the same time. For example, workers are affected by what happens in their home, 
by diseases and by drugs, by personal habits such as smoking and drinking, by exposure to hobby-agents such as glue, paints, solvents, and also by the environmental pollution of air, food, and water. Among the general population subjects are occupationally exposed; they are exposed by their own smoking habits, and by their hobby activities, etc., as well. Workers exposed to chlorinated hydrocarbon pesticides, and receiving drugs for treatment of epilepsia, have lower DDT/DDE levels in their body fat (10). In our laboratory we found higher carboxyhemoglobin levels in traffic policemen who smoked during their leisure time or office hours than in nonsmokers (3). In 1974 we studied the cadmium level in the blood of urban women (30); in those smoking 10 or more cigarettes a day the cadmium blood levels averaged $70 \%$ higher than in nonsmoking women. Thürauf et al. (21) measured cadmium levels in the placenta and observed an urban rural gradient; however they did not examine a possible difference in smoking habits between cities and rural areas and therefore forgot to take into account the microenvironment.

Therefore, occupational and public health workers carrying out biological monitoring programs should carefully evaluate potential exposure due to other spheres of human existence.

\section{BIOLOGICAL MONITORING AS AN EPIDEMIOLOGIC STUDY}

A biological monitoring program is nothing less than an epidemiologic study, i.e., a study of the distribution of parameters of health (in this case, of relevant internal exposure), and of its determinant factors, in groups of humans. Before starting an epidemiologic study, one always has to answer five questions, the $5 \mathrm{Ws}$, as explicitly as possible: who, what, where, when, why?

The answer to the question "Who?" specifies the group to be examined, and this should be the group thought to be most at risk. Such factors as age, sex, socioeconomic status, place of work or residence are important. In environmental health studies one often examines schoolchildren, because they can rather easily be ap- proached. However, very probably, preschoolchildren of $1-3$ years of age are the group most at risk, if one wants to evaluate exposure, e.g., to metals. There are four possible reasons for their increased risk: (a) increased exposure, because - being toddlers - they have excessive oral contact, (b) increased intestinal absorption, e.g., of metals, (c) different distribution through the body, e.g., for rapidly growing children relatively more lead in the trabeculae than in the dense bone, and so relatively more mobile lead, and (d) increased susceptibility, i.e., effects occurring at lower levels of internal exposure. It has been shown in studies from our laboratory (4) and by other workers that children $1-3$ years of age may have higher blood metal levels than children of 4 years of age and up.

In 1974 we examined adult women living at a distance of up to about $1.5 \mathrm{~km}$ from a secondary smelter with a main emission of lead. We did not, or hardly, see any effect on their blood lead levels or aminolevulinic acid dehydratase in comparison with controls. In the winter of 1976-1977 we examined the blood levels of 2- and 3year-old children living $<1 \mathrm{~km}, 1-2 \mathrm{~km}$, and $>2 \mathrm{~km}$ from the same smelter, the emission of which had certainly not increased (rather it had decreased between 1974 and 1976). We found a very clear distance effect; the young children formed a group much more at risk than the mothers.

However, this is not the whole story. We divided the children into two socioeconomic classes: SES I white collar, SES II blue collar. In the SES II children the blood lead levels were on the average 20$40 \mathrm{ppb}$ higher than in SES I children and this independently from distance to source (11). So it is clear that in this city young children of lower SES were more at risk than those of higher SES, and these children, again, were at higher risk than their mothers. If one studies schoolchildren, one may overlook the real population at risk.

At least as far as lead is concerned, one should also regard sex as one of the risk factors; it has been established in our laboratory $(20,24)$ and in Belgium by Roels et al. (17) that females have higher levels of free erythrocyte protoporphyrin than males at the same blood lead levels and that the rate of increase with in- 
creasing blood lead levels is higher. This phenomenon could also be true for schoolchildren, particularly at the age of puberty and adolescence.

However, preschoolchildren do not always constitute the group most at risk. One may also have to look for subjects with inborn errors of metabolism, particularly prevalent in some ethnic groups. In the case of carbon monoxide exposure one has to pay attention to older workers, particularly those with beginning deterioration of heart function. There exists suggestive evidence that manganese poisoning particularly occurs in workers with a specific distribution pattern throughout the body; maybe biological monitoring could serve to pinpoint such individuals.

An important aspect of the question "Who?" is the representativeness of the group examined. In occupational health an effort is usually made to examine all the workers exposed. Even if a few of them refuse to give blood, air or urine, a good insight of overall exposure can be achieved. In public health studies, however, the general population must usually be examined. The group cohesion is smaller, and there is less personal contact between health workers and the general public. It is much more difficult to achieve representativeness of the sample. Nevertheless, an attempt should be made, and the reports should explicitly discuss the limitations encountered.

Once more, in defining the population to be examined, one should not follow the easy way, i.e., use those that can be approached easily; instead, one should pay due attention to those most at risk, both in occupational and in public health studies.

The second question is What? Have the most relevant parameter and the most suitable biological specimen been chosen? If new research brings new facts, established biological monitoring methods may be doubted. Inhibition of cholinesterase, as a rather specific effect of exposure to organophosphate insecticides, has found its place in biological monitoring programs for estimating occupational exposure; if the inhibition does not exceed $20-30 \%$, it is regarded as acceptable. However, in recent years there is increasing evidence that, in workers with hardly any depression of cholinesterase, there may already exist a nonspecific decrease of conduction velocity in peripheral nerves. In our laboratory Verberk et al. (22) performed a human volunteer study. Eight male adults ingested $25 \mu \mathrm{g}$ mevinphos/kg of body weight for one month, and eight controls ingested a placebo. Cholinesterase was only inhibited for less than $20 \%$, i.e., by $>80$ $\%$ of the preexposure levels, and nevertheless a significant decrease in peripheral slow motor nerve conduction was observed. Measurement of cholinesterase inhibition is a good index for the prevention of acute organophosphate intoxication, but not for the prevention of subclinical effects on the peripheral nervous system. We have lost full confidence in cholinesterase inhibition as a parameter, but we have not yet found a useful substitute. Therefore, if we choose one or more parameters in biological monitoring programs, we should make very clear the relevance to health protection, i.e., what is the relationship between external exposure and the parameters examined, and what is the relation to health effects? In short, in applied biological monitoring programs, knowledge of the relationship between parameters of external exposure with parameters of internal exposure and with parameters of health effects is an essential condition.

Another aspect of the question "What?" is the biological specimen to be sampled. I will return to this subject later.

The third question is "Where?" The answer is usually determined by the specific local situation under study. However, one may have considerable difficulty in evaluating the various relevant environmental factors. In our country we are studying the relationship between hardness/softness of drinking water and cardiovascular health; a negative relation between hardness and cardiovascular mortality has been observed in two studies $(1,2)$. In our previous studies we did not take into account possible differences in metal contents and in type of waterpipe. Now a large-scale study has been started in cooperation with the water authorities. And we choose the sites to be compared much more carefully, taking note of, e.g., the metal composition of the water distribution systems. We are looking much more carefully into the question "Where?" 
than we did in the previous study. It is our hope that by doing this, we can not only confirm the previously established relationship, but also can receive more insight into the underlying mechanism.

The next question is "Why?" One should at least have an hypothesis on the exposure-response relationship. It is a waste of time to conduct routine biological monitoring studies without any reasonable idea of the "Why." That one can make a mistake if one too easily accepts an hypothesis, and so achieves completely unexpected results, was proved in a pilot study we performed last year. We discovered two adjoining communities, one with hard and one with soft water. We hypothesized that there would be low metal corrosivity in hard water areas and high corrosivity in soft water areas; therefore we expected levels of lead, cadmium, and zinc to be higher in water and in the blood of 40 - to 65-year-old women in the soft water area. However, this did not prove to be the case. At completion of the study, it was discovered that in the hard water area the $\mathrm{pH}$ was lower and the corrosivity therefore higher than in the soft water area, quite contrary to what is usually the case. We studied tapwater and blood at the same time, and only after completion of the pilot study did we discover that these twin communities could not be regarded as suitable pilot areas for a nationwide study. We should have tested the hypothesis of water corrosivity before doing all the work on the women. We learned a lot from this study, but not what we expected (23). Another finding was very interesting. It showed the great sensitivity of blood lead level as an indicator of comparably small differences in lead intake. In the hard water community the lead concentrations in the running tapwater were nearly all below the proposed CEC standard of $50 \mu \mathrm{g}$ lead/l, and already there was a positive correlation between the lead level in tapwater and in blood ( $\mathrm{r}=0.45, \mathrm{n}=37$ ).

One can only afford to do studies based upon assumed hypotheses in research studies, but in routine biological monitoring programs one should be reasonably certain of the answer to the question "Why?" before carrying out the program. In research programs there is more freedom to explore new approaches. The
Laboratory for Pharmacology, University of Nijmegen, is exploring an interesting line of research (19). There scientists are monitoring mercapturic acid excretion as a parameter for exposure to alkylating agents.

Then there still remains the question "When?" I will also return to it later.

\section{BIOLOGICAL MONITORING AND ENVIRONMENTAL MONITORING}

Why should biological monitoring be carried out in addition to, or even in place of, environmental monitoring? What are the advantages of biological monitoring? In answer to these questions I would mention the following.

1. I have already discussed the fact that biological monitoring may pinpoint the groups actually at risk much more adequately than environmental monitoring.

2. It may be much easier to estimate external exposure with the human body as the sampling instrument than with measurements of air concentrations. This is particularly true if the biological half-time is not too short, but more than, say, $5 \mathrm{~h}$. Variability in biological parameters will be much smaller than variability in, e.g., air and food concentrations.

3. Environmental monitoring does not usually take into account the physical work load and the respiratory minute volume. With the same external exposure, the internal exposure will be much higher during physical activity than during rest. In our laboratory Monster et al. (15) observed three times as high a respiratory minute volume and two-and-a-half to three times higher uptake of trichloroethylene in male volunteers during physical activity ( $100 \mathrm{~W}$ on an ergometer) in comparison to exposure at rest. Neither does environmental monitoring usually give any indication of percutaneous uptake.

4. Humans are exposed to many substances at the same time through various pathways. From the health point of view, 
primary interest is in total load, and not in the subload through only, e.g., air or food. This applies to many metals, pesticides, etc. What use is it to monitor only ambient air in cities like Mailand, where very probably because of the large use of wine there is an excessive intestinal uptake of lead? It appears to be nonsensical to set an air quality standard without knowledge of the base line of blood lead levels from uptake through other pathways. The same applies to carbon monoxide in ambient or workroom air and smoking habits and to pesticide levels in workroom air and food. The same may be said for occupational exposure to, e.g., solvents, which also penetrate through the skin.

5. Environmental monitoring of workroom air does not give any data on respiratory exposure in leisure time. Workers may be exposed to, e.g., trichloroethylene and also be glue sniffers; moonshine whiskey may also be consumed by lead workers. I have already mentioned the effect of smoking on carboxyhemoglobin and cadmium blood levels.

6. Environmental monitoring only gives a rough approximation of the actual dose received and of the expected internal exposure levels. If an agent is inhaled, it has to be absorbed, distributed, metabolized, and eliminated, and these biological mechanisms are to a large extent determined by individual characteristics. In our laboratory Monster et al. in an as yet unpublished study exposed five or six male volunteers to trichloroethylene, perchloroethylene and methylchloroform. There was a linear relationship between anthropometric measures such as lean body mass, body weight, minute volume and uptake of chlorinated hydrocarbon solvents at dosage levels of 70 and $140 \mathrm{ppm}$ for $4 \mathrm{~h}$ at rest; these anthropometric measures could be used for correction of, e.g., urinary data. One of the volunteers consistently showed a relatively high trichloroacetic acid level in blood and at the same time a relatively low trichloroacetic acid level in urine, in exposure to trichloroethylene, probably an indication of different pharmacokinetics - maybe the result of a higher binding capacity of his blood.
In Prague Sedivec and Flek (18) conducted human volunteer studies with xylene and examined the relation between xylene metabolites in urine and the actual dose received. They demonstrated that correcting urine levels with data on body length and ideal body weight highly narrowed the confidence limits and so increased the reliability of prediction of the dose received.

By taking into account these individual characteristics of anthropometry, pharmacokinetics, work load, etc., one can decrease the variability of the data deserved and so achieve a better prediction of actual exposure levels of groups or individuals. Biological monitoring also takes into account the effect of (prae)pathology and use of drugs, e.g., the already mentioned effect of consumed enzyme inducing drugs of DDT levels; it is well known that in cadmium exposure urinary cadmium levels increase when renal function becomes impaired.

Biological monitoring tells us much more about the relevant exposure than environmental monitoring does, and in certain cases it may even furnish information on health effects. Biological monitoring provides much better possibilities than environmental monitoring for the consideration of the individual characteristics of exposed subjects. I regard this as one of the main advantages of biological monitoring; biological monitoring is a medicobiological approach, and so a better tool for health protection.

7. An additional advantage of biological monitoring is that it not only allows the measurement of several exposure parameters simultaneously in one biological specimen, e.g., in the case of mixed solvent or metal exposure, but also health effect parameters such as, e.g., hemoglobin, cholesterol, bilirubine, serum enzymes. In the recent international workshop on metalmetal interaction, convened in Stockholm in July 1977, it was recommended that in occupational health studies one should much more often examine the biological specimen for all or most of the metals to which one is often exposed in mixed industrial exposure. The same recommendation applies of course to, e.g., solvents and pesticides. One may elucidate sug- 
gestive evidence of biological interaction. Our laboratory has data which at least suggest that, both in occupational and in ambient exposure to lead, manganese in blood increases, probably as a biological effect of lead exposure. At this moment, however, the evidence is not yet conclusive (29). Animal experiments are being carried out to test this hypothesis.

8. To the final point of advantage I will refer later on: i.e., to the fact that biological monitoring of exposure may require much less expenditure in time and manpower than environmental monitoring.

\section{LIMITATIONS OF BIOLOGICAL MONITORING}

However, biological monitoring should not be regarded as the only method of choice. There also exist the following severe limitations.

1. Biological monitoring requires human beings as sampling units. This situation may mean a certain inconvenience for the subjects; it may create anxiety, emotion. I will return to this subject later.

2. No reliable and/or convenient biological parameter of exposure for many agents and/or metabolites exists. There is still much work to be done. Levels in, e.g., the liver, kidneys or brain of living beings cannot be measured. However a new method for the noninvasive measurement of cadmium concentrations in liver by means of neutron-activation analysis looks promising (8).

3. Data on levels of agents or metabolites are often widely published. I have already stated that - notwithstanding sometimes abundant data - there is often not enough reliable information. It may sometimes be possible to suggest a relationship between average external exposure levels and average parameters of internal exposure in groups. One should not be content with average levels, but instead should aim at individual monitoring to elucidate interindividual variability. Scientists are still far from reliable data on individual monitoring.

In recent years anesthesiologists have become concerned about the health effects of exposure to various halogenated anesthetics. If one reviews the literature, one finds many data on urine or blood levels of, e.g., fluorine, bromine, halothane, but external exposure data are very insufficient. Most of the work has been performed by anesthesiologists who have no idea about the rigid approach necessary for measuring external exposure.

In our report to CEC we concluded that current knowledge does not yet allow proposals for reliable biological permissible levels for most of the halogenated hydrocarbons - solvents and anesthetics reviewed; this certainly applies also to many other agents (16).

4. If one reviews literature over many years, one can often see systematic trends in levels measured in nonoccupationally exposed subjects; they usually tend to become lower. This is largely an artifact: improvement in analytical techniques. Older studies have served their role. They showed the possibility for approach, but from the quantitative point of view there were many deficiencies. However, I am sorry to say that this applies as well to recent studies. In 1974, in the CEC-EPAWHO Symposium on recent advances in the assessment of health effects of environmental pollution, we were informed that nonoccupationally exposed subjects living in the vicinity of a copper smelter in Wroclaw, Poland, had blood lead levels of 1,820 ppb (5). This is about 10 times the levels reported in Dutch and Scandinavian populations. The audience was quite astonished, but could not convince the speaker that very probably there was something wrong with the analytical techniques. Last year when I gave a lecture in that city, one member of my Polish audience brought forward the same data again. Interlaboratory studies can easily be proposed, but, when I did so in an East-European country, there appeared to be only one or two atomic absorption spectrometers available in the whole country. So hŏni soit qui mal $y$ pense. 
5. Biological monitoring cannot be aplied for agents which do not enter the body fluids. Sampling of feces is certainly a valid method for monitoring a few metals and maybe asbestos fibers, but for understandable reasons it is not often carried out. There is no possibility to use biological monitoring for such surface acting agents as chlorine, ozone, nitrogen oxide, peroxyacetylnitrate, hydrogen chloride, and sulfur dioxide.

6. External exposure may vary greatly with time, and, when at the same time the agents exert an acute health effect and/or the biological half-time is very short, a routine biological monitoring program may fail in its objectives. Such a program does not prevent incidental acute overexposure.

Biological monitoring may be very promising; it also has its limitations. It certainly cannot replace environmental monitoring; often one has to apply both approaches.

\section{TYPE OF SPECIMEN AND TIME OF SAMPLING}

In routine monitoring it is crucial to examine the right parameter in the right biological specimen at the right point of time in the right population at risk. What is "right" is determined by the specific objective of each program, and also by the demands of the practical situation under study.

Discussing the ins and outs of a practical program in occupational health in exposure to chlorinated hydrocarbon solvents, I will use recent, not yet published data from human volunteer studies and an epidemiologic study, carried out by my coworker Monster. This example certainly does not cover all aspects of biological monitoring in occupational health practice, but it may illustrate various points which have a wider area of interest for the biological monitoring of other agents.

We performed the following humanvolunteer studies with exposure to trichloroethylene: (a) $70 \mathrm{ppm}-4 \mathrm{~h}-$ rest

(b) $70 \mathrm{ppm}-4 \mathrm{~h}-$ rest $+2 \times 0.5 \mathrm{~h}$ physical exercise on an ergometer at $100 \mathrm{~W}$

(c) $140 \mathrm{ppm}-4 \mathrm{~h}-$ rest

(d) $140 \mathrm{ppm}-4 \mathrm{~h}-$ rest $+2 \times 0.5 \mathrm{~h} \cdot 100$ $\mathrm{W}$

(e) $70 \mathrm{ppm}-4 \mathrm{~h} \times 5$ days - rest

In each experiment four to five adult males took part. Because respiratory minute volume was also measured, we could calculate the actual dose received: in a, $390 \mathrm{mg}$; in b, $520 \mathrm{mg}$; in c, $755 \mathrm{mg}$; in d, $1,055 \mathrm{mg}$; in e, $5 \times 450 \mathrm{mg}$ (average values).

In contrast to most studies published, we always examined all three practical biological specimens available (exhaled air, blood, urine) for the following parameters at the same point in time, if possible: trichloroethylene (TRI), trichloroethanol (TCE), trichloroacetic acid (TCA).

The purpose of our experiments was to study (a) the trend of parameters over time in the postexposure period, (b) the predictive power of various parameters in regard to the individual dose received, (c) the accumulation of TRI, TCE and TCA in the 5-day experiment, (d) the predictive power of various parameters of the 4-h exposure in regard to the parameters in the $5-\mathrm{x}-4-\mathrm{h}$ exposure, and (e) the influence of work load on uptake.

In industry one is limited in the possibilities for sampling in regard to practical points of time. Probably the most convenient times both for workers and for management are (a) during or directly after work, i.e., at $\mathbf{0} \mathrm{h}$ postexposure, (b) the following morning before starting work, i.e., at $16 \mathrm{~h}$ postexposure, and (c) after the weekend before starting work, i.e., at $60-64 \mathrm{~h}$ postexposure.

It is not practicable to examine 24-h urine samples. I know from my own experience that in one factory workers from three successive day and night shifts solved this problem in a very practical way; they each voided urine only during their own shift, and produced a mixed 24-h sample. This very practical solution is not very helpful.

In our experiments we worked out the data for 0 - to $2-\mathrm{h}, 16-\mathrm{h}$ and 60 - to $64-\mathrm{h}$ postexposure. For lipid soluble agents, one can make the general conclusion that sam- 
pling at $0-2 \mathrm{~h}$ yields information on the exposure during the last phase of work; sampling at $16 \mathrm{~h}$ gives reliable information on the overall exposure level during the previous day; sampling at $60-64 \mathrm{~h}$ yields information both on overall exposure during the previous work week and on individual anthropometric characteristics, particularly the fatty mass of the subjects.

A drawback of sampling exhaled air is that one usually can only measure the agent itself; therefore, one has to perform the test in a noncontaminated room, outside the workplace. However, Monster and his colleagues $(14,15)$ demonstrated that TCE is a volatile metabolite that is present in exhaled air. So, one can also apply biological monitoring at the workplace itself, at least in exposure to TRI. Another drawback is that, immediately following exposure, the concentrations in exhaled air are, to a large extent, determined by the exposure levels at the end of the workday and so do not give an indication of exposure over a 4- to 8-h period; this is true for TCE in exhaled air to a lesser degree, however.

The second medium is blood, which has the disadvantage of involving greater inconvenience than the sampling of breath or urine.

The third specimen is urine, up to now the specimen of choice in occupational medicine. One can measure the concentration as such, the concentration corrected to creatinine content and the amount excreted in a certain period of time (i.e., timed sampling).

Monster et al. (14) developed a gas chromatographic method by which, in blood, air or urine, the solvents TCE and TCA could be measured in one analysis. This procedure also makes it possible to examine the predictive value of measuring one, two or three parameters simultaneously as a predictor of dose received.

In the experiment with 4 -h exposure to TRI for one day, we studied the predictability of the individual dose received, based upon the various biological data measured; there were four subjects and four conditions, i.e., 16 points on each regression line. The coefficients of variability (x 100) of the predicted dose received are shown in table 1 (only presented for coefficients $\leq 25$ ).
Table 1. Coefficients of variability $\leq 25$ (x 100) of the predicted dose.

\begin{tabular}{|c|c|c|c|}
\hline \multirow{2}{*}{ Specimen } & \multirow{2}{*}{ Parameter a } & \multicolumn{2}{|c|}{ Point in time } \\
\hline & & $0-2 \mathrm{~h}$ & $16-20 \mathrm{~h}$ \\
\hline $\begin{array}{l}\text { Exhaled } \\
\text { air }\end{array}$ & $\begin{array}{l}\text { TRI } \\
\text { TRI + TCE }\end{array}$ & $\begin{array}{l}24 \\
25\end{array}$ & 一 \\
\hline Blood & $\begin{array}{l}\text { TRI } \\
\text { TCA } \\
\text { TRI-TCE }+ \\
\text { TCA }\end{array}$ & $\stackrel{16}{-}$ & $\begin{array}{l}\overline{21} \\
15\end{array}$ \\
\hline Urine & $\mathrm{TCE}+\mathrm{TCA}$ & - & - \\
\hline
\end{tabular}

a $\mathrm{TRI}=$ trichloroethylene; $\quad \mathrm{TCE}=$ trichloroethanol; $\mathbf{T C A}=$ trichloroacetic acid.

Table 2. Caefficients of variability $(\leq 25)$ found in an $4 \mathrm{~h}-5$ day exposure experiment with tricholoroethylene.

\begin{tabular}{|c|c|c|c|}
\hline \multirow{2}{*}{ Specimen } & \multirow{2}{*}{ Parameter a } & \multicolumn{2}{|c|}{ Point in time } \\
\hline & & $0-2 \mathrm{~h}$ & $60-6 \mathrm{~h}$ \\
\hline $\begin{array}{l}\text { Exhaled } \\
\text { air }\end{array}$ & $\begin{array}{l}\text { TRI } \\
\text { TCE }\end{array}$ & 17 & - \\
\hline Blood & $\begin{array}{l}\text { TRI } \\
\text { TCE } \\
\text { TCA }\end{array}$ & $\begin{array}{l}21 \\
21 \\
11\end{array}$ & $\frac{-}{15}$ \\
\hline Urine & $\begin{array}{l}\text { TCE } \\
\text { TCA } \\
\text { TCE + TCA }\end{array}$ & $\begin{array}{l}-\overline{22} \\
-\end{array}$ & - \\
\hline
\end{tabular}

a TRI = trichloroethylene $; \quad$ TCE $=$ trichloroethanol; TCA $=$ trichloroacetic acid.

Table 3. Coefficients of variability of the concentration-time product predicted from the biological parameters in an epidemiologic study with tetrachloroethylene.

\begin{tabular}{llcc}
\hline \multirow{2}{*}{ Specimen } & Parameter a & \multicolumn{2}{c}{ Point in time } \\
\cline { 3 - 4 } & & $\begin{array}{l}\text { Day 5, } \\
0-2 \mathrm{~h}\end{array}$ & $\begin{array}{c}\text { Day } 5+2, \\
60-64 \mathrm{~h}\end{array}$ \\
\hline Exhaled & & & \\
air & PER & 18 & - \\
Blood & PER & 20 & - \\
& TCA & - & - \\
Urine & TCA & 18 & - \\
\hline
\end{tabular}

a $\mathrm{PER}=$ tetrachloroethylene; $\mathrm{TCA}=$ trichloroacetic acid. 
The predictive value increases with decreasing coefficients of variability; it therefore may be concluded that monitoring blood at $0-2 \mathrm{~h}$, or at $16-20 \mathrm{~h}$ yields the best prediction of individual dose received, particularly when TRI and both metabolites are measured simultaneously, which hardly increases the analytical load over the measurement of only one parameter. Monitoring urine is far inferior to monitoring blood or exhaled air.

In the $4 \mathrm{~h}-5$ day exposure experiment, we had only one condition (70 ppm TRI), and hence there was too little variation in the doses received for a regression line to be calculated. Therefore we compared the coefficient of variability ( $x$ 100) of the biological parameters after five exposures over five subjects; good predictors will have a low coefficient of variability. The coefficients $\leq 25$ are presented in table 2 . Here again, the lowest coefficient of variability is observed when blood is used as the sampling medium. In 5-day exposure, accumulation takes place, particularly of TCA, and this parameter provides the lowest variability.

We also performed human volunteer studies with exposure to tetrachloroethylene and 1,1,1,trichloroethane (methylchloroform). Because biotransformation to TCE is much less than in the case of TRI, we have mostly to rely on measurement of the agent itself in exhaled air or blood.

Recently we did an epidemiologic study with nine workers in a dry-cleaning shop, with high exposure to tetrachloroethylene; for each worker we could calculate a concentration-time product, based upon personal sampling and exposure duration. The coefficient of variability of the concentration-time product, predicted from the biological parameters, was as shown in table 3 (only coefficients of variability of $\leq \mathbf{2 5}$ presented). In this case, we found about the same coefficient of variability for air, blood and urine samples taken on Friday at the end of exposure.

The data reported only serve as examples; the full data will be published by Monster in the near future. The examples show clearly that type of biological specimen, type of parameter, and point in time should all be taken into account when a biological monitoring program is designed, and, moreover, that urine may often be inferior to blood or exhaled air as a sampling medium.

Now it is time to discuss an ethical question. The Fujiwara reaction, measuring TCA in urine of workers exposed to TRI, is still the method of choice in many industries. It can certainly be used to indicate rather high exposure in groups. However, exposure levels fortunately decrease, and more attention should be paid to individuals at risk. I have already shown that in one of the volunteers a different type of biotransformation (more TCA in blood) and elimination (less TCA in urine) existed. Our studies and also those of others have shown that measuring metabolites in urine gives only a very poor prediction of the TRI dose received. Now the ethical question. Too easily occupational physicians claim that they need simple methods that can be performed quickly, cheaply and by low-trained personnel. It would be foolish not to use simple methods if they give an adequate extimate of exposure or if, in this way, one could easily exclude unacceptable exposure levels. I believe that in exposure to lead the very simple zinc protoporphyrin method can be used to a very great advantage for the exclusion of blood lead levels over 400 or $600 \mathrm{ppb}$ in individuals; only if zinc protoporphyrin exceeds certain levels, should more sophisticated methods of blood lead analysis be applied. But simple methods can be applied only if one can have confidence in the results. In the case of chlorinated hydrocarbon solvents, the Fujiwara reaction in urine does not give an adequate answer. Management hires highly qualified engineers and technicians, equipped with very expensive apparatus, to check production processes and the quality of the machines. But occupational health too easily makes use of simple, inadequate methods. Is a worker less important than a machine? Therefore, I want to stress that society has a duty to protect workers' health, and to prevent overexposure; therefore the tools needed to measure exposure levels adequately should be used. If one has to apply sophisticated methods and to employ highly trained technicians making use of expensive apparatus, then one will have to do so. It 
is a question of ethics, both of the occupational physician and of management, to provide the tools for the optimal protection of workers.

\section{AVERAGING OF DATA}

An average human being does not exist; there is no standard Dutchman, Russian, or Finn. We all constitute odd mixtures of capabilities and of exposure levels, of personal preferences, of defense mechanisms to eliminate xenobiotic agents, etc. However, in many, probably in most, publications on biological monitoring the data are given as the arithmetic average and standard deviation. This is only allowed in the case of Gaussian distributions. However, it is well known that nonessential metals and other xenobiotics do not usually distribute normally, but follow a skewed, often log-normal, distribution.

In the well-known paper by Grandjean et al. (7), often quoted in documentations on threshold limit values for trichloroethylene, the authors derive a relation between TCA in urine to TRI in air of about $3: 1$; however, the range is from 20:1 to 1:2, i.e., covering a factor of 40. This often-quoted quotient of TCA to TRI does not give any valid information.

Hassman and Hassmanova (9) presented information on TCA and TCE concentrations in urine of workers exposed to carbon tetrachloride; the average concentration of TCA was $2.6 \pm 7.8 \mathrm{mg} / 1$, and that of TCE $33.5 \pm 44.4 \mathrm{mg} / \mathrm{l}$. If these data are interpreted as presented, then there must have been negative metabolite levels in the urine. Moreover, it is highly improbable that carbon tetrachloride will be metabolized into compounds with two carbon atoms, so there may have been mixed exposure.

If the geometric average is used, then one may receive more valid information, but often even this is not enough. In a town, or within a factory department, there may be a local source which affects only a part of the group examined. It may be that $10 \%$ have very high levels, $20 \%$ have only moderately increased levels, and $70 \%$ have normal levels. Only by making a percentile distribution, i.e., the percen- tages not exceeding specified levels, can one get relevant data.

As a physician responsible for occupational and/or public health one should first of all pinpoint those individuals or groups of subjects with the highest internal exposure levels. This cannot be achieved with a preconceived idea that average human beings are being dealt with; instead one must pay due attention to the extremes, i.e., the tails of the distribution. The easiest way to find these subjects is to work up the data as a percentile distribution. Too easily the same statistical methods are applied during the processing of animal and human data. However, experimental animals usually come from an inbred stock of rather similar genetic make up; they grow up under similar environmental and nutritional conditions and are exposed under highly controlled, but very unnatural, conditions. On the other hand - fortunately enough - human beings are not reared in a rigidly controlled room, and they choose their own partners for reproduction. Diversity is the rule. So, in epidemiologic studies attention should be focused on dissimilarity, and not on similarity.

\section{DESIGN OF BIOLOGICAL MONITORING PROGRAMS}

It should have become clear by now that there does not exist any overall design for biological monitoring programs. Each specific program has to be designed according to the explicitly stated objective and the local situation. The design is determined by many factors.

1. First of all the aforementioned five Ws must be answered. Which is the group at risk; do we want to study individual or group exposure? What is the agent or agents concerned; is there a short, an intermediate or a very long biological half-time? For lead in stable environmental exposure one may use hair, but probably not in variable occupational exposure. For methylmercury hair proves to be a better medium than for inorganic mercury. Phenol excretion gives information on recent benzene exposure during the workday, but benzene in exhaled air presents 
better information on the extent of saturation of fatty tissues in repeated exposure. One may use lead levels in deciduous teeth as a historical picture of exposure in the past. Levels in feces provide information on exposure to metals and probably asbestos. Biological monitoring techniques may be applied for following exposure levels over many years (longitudinal studies) or comparing exposure levels (transversal studies) from various work departments, industries or, in case of environmental exposure, from various regions or countries.

2. The design is also determined by the local situation; i.e., what is considered inconvenient, what level of cooperation from the subjects can be achieved. In the case of young children it will be much more difficult to obtain blood than from schoolchildren and adults. Trade unions may bring forward the too often heard objection that biologically monitored workers are used as guinea pigs.

3. A program for periodic biological monitoring will have different requirements than a program for one-time surveillance; in the latter one may have to measure a more complete set of parameters than in the former.

4. The required frequency of periodic biological monitoring does not follow any general rule. It depends on the variability and the intensity of exposure, the toxicity of the agent, and the pharmacokinetic properties, short versus long biological half-time.

5. Manpower and budget may be limitative; samples may have to be sent to other laboratories for analysis.

It is not possible to discuss the design of biological monitoring more fully, because each agent and group at risk may have its own specific requirement. There is one more general principle I want to mention however. The design also depends upon a set of general questions asked: do we want to exclude harmful exposure, do we want to estimate the level of exposure in groups, or do we want to follow an individual with possible overexposure? In the first case, one or several tests may be applied, some- times even semiquantitative ones. If the levels do not exceed predetermined figures, then there is no harmful exposure. Examples are: zinc protoporphyrin in blood and aminolevulinic acid or coproporphyrin in urine can be used to exclude relevant exposure to lead; phenol excretion below 15 $\mathrm{mg} / \mathrm{l}$ of urine excludes relevant recent exposure to benzene; mercury levels below $50 \mu \mathrm{g} / 1$ in urine exclude relevant occupational exposure to inorganic mercury. These examples indicate that biological monitoring will give an adequate picture of overall exposure at a much less expenditure of time, manpower and budget than environmental monitoring; biological monitoring may make environmental monitoring quite unnecessary.

If, on the other hand, definite increased exposure exists, one will have to apply a more elaborate set of parameters and also may have to include indicators of health effects, e.g., in the case of lead hemoglobin, free erythrocyte/zinc protoporphyrin and blood lead levels; in the case of cadmium also protein in urine; in the case of benzene maybe also blood counts. In addition in occupational health the physician himself will have to see the individual workers, and will at least gather a first impression of subjective and objective health.

If biological monitoring is applied to follow up the sequence of effects in an individual at risk, maybe in recovery from clinical poisoning, then biological monitoring will be a part of a total clinical examination which encompasses a broad set of tests.

\section{BIOLOGICAL PERMISSIBLE LIMITS}

If there exists a reasonable relationship between external exposure and parameters of internal exposure, then there must also exist levels of agents or metabolites in the biological specimen which correspond with permissible limits of exposure. As a physician I regard biological permissible limits (BPLs) as superior to environmental limits, and I consider it an important task to develop such biological permissible levels.

Last year I had the opportunity to discuss the facts, fallacies and fancies of permissible levels for workroom air in a 
course on standard setting organized by the Danish Society of Industrial Medicine (28). Published TLVs (threshold limit values) and MACs (maximum acceptable concentrations) are relied on a great deal, but the confidence put in these levels may have to be seriously doubted. Should there be the same doubts about BPLs? In my opinion they are at least as reliable, and probably even more reliable, than permissible levels for workroom or ambient air, mainly because biological monitoring approaches the total exposure better, as far as is relevant for health, and because it accounts for aforementioned biological factors.

Various lists of BPLs are being published, but they usually refer to average group levels, whereas the actual task is to protect small groups or individuals at risk. That is the reason I prefer BPLs based upon percentile distributions.

Three years ago I proposed, to the CEC, a biological quality guide for blood lead levels for the general population based upon the following reasoning (25).

1. Various no-adverse effect levels are available, so certain individual blood lead levels can be used as the maximum permissible.

2. Because a group of the general population is composed of individuals with different food and water intake, with different personal habits, there will be different blood lead levels. The percentile distributions must be calculated as they occur in general populations with nonadverse exposure to lead.

3. A biological quality guide for a general population cannot take into account those few individuals with life situations which are to be regarded as exceptional and which may induce high blood lead levels. Public health authorities cannot base their actions on a few odd people; they should instead be protected in an individualized approach. Quite arbitrarily I have set these individuals at $2 \%$ of the general population.

4. The survey should be directed at those individuals most at risk, from the viewpoint of possible environmental exposure and of possible health risk. So, housewives and preferably young children should be studied, and not adult males, who may also be exposed in their work situation.

Using these four principles, I came to the following proposal: The percentile distribution of blood lead levels in groups of 50 to 100 housewives or children should not exceed $200 \mathrm{ppb}$ in $50 \%, 300 \mathrm{ppb}$ in $90 \%$, and $350 \mathrm{ppb}$ in $98 \%$ of the population studied. This proposal has gone through various committees within the CEC, and in the beginning of 1977 it was accepted by the Council of Ministers. From 1977 on a survey program (2 years; 50 subjects for each million population; and in cities with over 1 million inhabitants, at least 50 per 0.5 million) will be carried out in all nine CEC countries. If the percentile distribution does not exceed this biological quality guide, one need not bother about the source of lead exposure, and the money and manpower that would have been spent can be used for better purposes.

I submitted my proposal in 1974. Now three years later I have some doubts as to whether the biological quality guide protects young children enough. Maybe it has to be lowered to, e.g., $98 \%<300$ ppb. However, the program has just started within the CEC, and it will be too difficult to change the regulations on short notice. A CEC workshop on the feasibility of adding free erythrocyte protoporphyrin or zinc protoporphyrin measurement as a prescreening procedure is being planned. If accepted, it would make the survey much easier and would leave the more sophisticated blood lead analysis for those subjects with free erythrocyte protoporphyrin or zinc protoporphyrin levels exceeding certain values.

Biological quality guides can probably be worked out for other agents also, e.g., for the level of mercury, cadmium, manganese, or carboxyhemoglobin in appropriate biological specimens. We have begun to use a new method of biologically monitoring a population, and I sincerely hope that this approach will be followed by others. One could also apply this method to nonhuman targets, e.g., mercury levels in fish, and to other areas of biotoxicity.

In occupational health there is also an urgent need for BPLs for workers. The recent $\mathrm{CEC}$ review of literature has as its 
main objective to prepare the way for proposals of BPLs for workers. However, reliable levels are limited. On the other hand, if the same sometimes poor level of reliability is applied as in the case of permissible limits for workroom air, more use could and should be made of already existing information.

In 1968 our laboratory organized an international workshop on permissible limits for occupational exposure to lead, and we came to the following proposals: $\mathrm{PbB}<700 \mathrm{ppb}, \mathrm{PbU}<130 \mathrm{ppb}$. Last year we held a second workshop to reevaluate our previous proposal, in view of the new information available (27). This time we also explicitly stated that we set the maximum BPLs for individual workers, and - I believe for the first time in history - we set different levels for adult males and females: male $\mathrm{PbB} \leqslant 600 \mathrm{ppb}$, females $\leqslant 400 \mathrm{ppb}$.

In another international workshop, organized by our laboratory in 1971 (12), on permissible levels of pesticide exposure, we derived the BPLs listed in table 4. Had the same workshop been held very recently, in view of new information on peripheral nervous system effects, we would probably have been less confident in proposing a level for cholinesterase inhibition.

In November last year in Paris an international workshop on benzene was organized by Truhaut. We proposed the following BPLs for phenol in urine: about $50 \mathrm{mg}$ of phenol/1 indicates exposure to $80 \mathrm{ppm}-$ $\mathrm{h}$ (10 ppm, $8 \mathrm{~h}$ ), over $25 \mathrm{mg} / \mathrm{l}$ indicates some benzene exposure, less than $10 \mathrm{mg} / 1$ probably indicates absence of significant exposure.

Recently my coworker Verberk reprocessed already 6-year-old data on bromine levels in the blood of 33 workers exposed to methyl bromide; an encephalogram (EEG) had also been taken. The preliminary conclusions were as follows: In workers with blood bromine levels of $>12$ $\mathrm{mg} / \mathrm{l}$, there is a 3.5 times higher risk for slight EEG disturbances than in those with blood bromine levels of $<12 \mathrm{mg} / \mathrm{l}$. One certainly cannot yet regard these data as conclusive, but at least they indicate a promising approach for biological monitoring in the case of methyl bromide exposure.

These few examples may illustrate the feasibility, and - I think - also the duty, to do more research on developing BPLs and also on applying them in practice. If available, they probably provide better protection than merely confidence in levels in workroom air or in ambient media.

\section{ETHICAL ASPECTS}

Biological monitoring uses human subjects as sampling units; therefore a biological monitoring program should always be carried out under the direct supervision of medical authorities; it is a medical procedure, even though the sampling and analytical techniques may lie outside the field of medical discipline.

When biological monitoring is being designed and carried out, the following points should always be seriously discussed:

1. Is biological monitoring really necessary or highly advantageous for the achievement of the objective? Can the data also be gathered by other means just as well, e.g., through environmental monitoring?

2. Is a specific biological monitoring program a part of a total approach? If

Table 4. Suggested guidelines for pesticide absorption and response (levels in blood).

\begin{tabular}{lllc}
\hline Pesticide & No harmful effect & Action required & Temporary removal \\
\hline & & & \\
Total DDT & $<0.2 \mu \mathrm{g} / \mathrm{ml}$ & $0.2-0.5 \mu \mathrm{g} / \mathrm{ml}$ & \\
$\begin{array}{l}\text { Dieldrin } \\
\text { Cholinesterase }\end{array}$ & $0.1 \mu \mathrm{g} / \mathrm{ml}$ & $0.1-0.2 \mu \mathrm{g} / \mathrm{ml}$ & $>0.2 \mu \mathrm{g} / \mathrm{ml}$ \\
inhibitors & $<30 \%$ inhibition & $>30 \%$ \\
& $\quad$ preexposure level & \\
\hline
\end{tabular}


necessary, biological monitoring should be followed by a program of technical prevention. The results should really affect future exposure levels.

3 . Is the design valid? Can the data to be obtained really answer the specific objective of the program? Have the five Ws been answered?

4. Is the biological monitoring program organized efficiently enough so that the inconvenience to the subjects is in proportion to the results that can be expected? Is relatively too much time demanded from workers, and therefore a conflict with management created?

5. Does the method carry any health risk? There is always the difficulty, in studies of "healthy" subjects, that the investigator is much more limited in application of techniques than in clinical studies in a hospital. In addition changes must be measured which may be small in comparison to changes seen in "sick" subjects. An epidemiologist has to catch small fish in a net with wide mesh, whereas a clinician catches large fish with fine mesh. It is not possible to use liver puncture, lumbar puncture, etc., in biological monitoring programs.

6. Does the biological monitoring program induce emotional unrest and anxiety? Was well-planned information given to the workers or the general public before a program began?

7. Is the confidentiality of individual data guaranteed? Subjects themselves and their general practitioners should be informed of the individual results; management and government officials should be informed of the group data. One of the problems is that general practitioners often know very little about the significance of, e.g., metal or pesticide levels; so there should also be an information program for them. The group data, together with an evaluation, should not only be made available to management and to government, but also to workers, unions and the general population themselves. In this way they themselves can check whether the necessary measures are being carried out by management or government.
8. Is the freedom of individuals to refuse to take part in a biological monitoring program guaranteed? Is undue social pressure put on them? There is always conflict between representativeness of a sample and the liberty to refuse participation. However, the liberty of individuals should not be sacrificed, if this liberty does not endanger fellow beings.

9. Is the biological monitoring carried out according to local and national rules and laws on matters of legal responsibility?

In occupational health it is the prime responsibility of the medical department to establish a high level of confidence and cooperation. This will, to a large extent, be based upon skill and knowledge, and on attitude showing a real concern with health protection. In public health work the personal contact with the public is bound to be less close; therefore an extra input of information is needed, e.g., the organization of discussion meetings. Only when workers or the general public see the reasoning behind a program, and have achieved confidence in the medical authorities, can a biological monitoring program be carried out without undue emotion and anxiety.

\section{CONCLUSION}

In this paper several principles of biological monitoring have been discussed. I took the liberty of using those examples I personally have been involved with and possibly created the completely false idea that other examples from the literature were not good enough. This certainly is not the case. Much work is going on everywhere, not the least in the Scandinavian countries. However, an enormous task still lies ahead. It was the purpose of this paper to further an understanding of the general principles and to promote more extensive exploration and application of the possibilities of biological monitoring, both in occupational and in public health. 


\section{REFERENCES}

1. BIERSTEKER, K. Drinkwaterzachtheid en sterfte [Soft drinking water and mortality]. Tijdschr. soc. geneesk 45 (1967) 658-661.

2. BIERSTEKER, $K$. and ZIELHUIS, R. L. Hard of zacht drinkwater? [Hard or soft drinking water]. Tijdschr. soc. geneesk. 53 (1975) 3-9.

3. BRUIN, A. DE. Carboxyhemoglobin levels due to traffic exhaust. Arch. environ. health 15 (1967) 384-389.

4. CASTILHO, P. DEL, WIBOWO, A. A. E., SCHUTGENS, R. B. H. and ZIELHUIS, R. L. Orienterend onderzoek naar het gehalte van enkele sporemetalen in het bloed van jonge kinderen [Explorative study of trace metal levels in blood of young children] Tijdschr. soc. geneesk. 55 (1977) 470-472.

5. DOBRYSZYCKA, W., IWANKIEWICZ, S., JACYSZYN, K., KOTLAREK-HAUS, S., OLEKSYK, E. and STANKOWSKA, K. L'influence des pollutions industrielles de l'air sur l'organisme humain. In: Recent advances in the assessment of the health effects of environmental pollution (vol. II). Commission of European Communities Luxembourg 1975, p. 685-691.

6. COMMISSION OF EUROPEAN COMMUNITIES - WORLD HEALTH ORGANIZATION - U.S. ENVIRONMENTAL PROTECTION AGENCY. Symposium on "The Use of Biological Specimens for the Assessment of Human Exposure to Environmental Pollutants" 18-22 April 1977. (In press)

7. GRANDJEAN, E., MÜNCHINGER, R., TURRIAN, V., HASS, P. A., KNOEPFEL, $\mathrm{H}$. K. and ROSENMUND, H. Investigations into the effects of exposure to trichloroethylene in mechanical engineering. Br. $j$. ind. med. 12 (1955) 131.

8. HARVEY, T. C., THOMAS, B. J., MC LELLAN, J. S. and FREMLIN, J. H. Measurement of liver-cadmium concentrations in patients and industrial workers by neutron-activation analysis. Lancet 1 (1975) $1269-1272$.

9. HASSMAN, P. and HASSMANOVA, V. Werte von Trichloressigsaüre und Trichloräthanol im Harn bei den unter einem Tetrachlormethan- und Methylchloridrisiko arbeitenden Personen. Int. Arch. Gewerbepath. Gewerbehyg. 25 (1969) 299306.

10. HAYES, W. J. Toxicology of pesticides. Williams and Wilkins, Baltimore, Md. 1975.

11. HERBER, R. F. M., WIBOWO, A. A. E., ZIELHUIS, R. L. and CASTILHO, P. DEL. Lood, cadmium en vanadiumgehaltes in bloed van kinderen in Arnhem wonend nabij een industrieterrein $[\mathrm{Pb}, \mathrm{Cd}$ and $V$ blood levels in children out of Arnhem, living in the vicinity of a secondary smelter]. Coronel Laboratory, Amsterdam 1977. $10 \mathrm{p}$.

12. INTERNATIONAL WORKSHOP. Epidemiological toxicology of pesticide exposure. Arch. environ. health 25 (1972) 399-405.
13. LEGATOR, M. S. and HOLLAENDER, A. (eds.). Occupational monitoring for genetic hazards. Ann. n. y. acad. sci. 269 (1975).

14. MONSTER, A. C. and BOERSMA, G. Simultaneous determination of trichloroethylene and metabolites in blood and exhaled air by gas chromatography. Int. arch. occup. environ. health 35 (1975) 155-163.

15. MONSTER, A. C., BOERSMA, G. and DUBA, W. C. Pharmacokinetics of trichloroethylene in volunteers, influence of workload and exposure concentration. Int. arch. occup. environ. health 38 (1976/7) 87102.

16. MONSTER, A. C., STEINBUSH, G. and ZIELHUIS, R. L. Biological monitoring in occupational health; halogenated hydrocarbons, a literature review. Submitted to CEC-Occupational Health, 1977.

17. ROELS, H. A., LAUWERYS, R., BUCHET, J. P. and VRELUST, M. T. Response of free erythrocyte porphyrin and urinary $\delta$ aminolevulinic acid in men and women moderately exposed to lead. Int. Arch. Arbeitsmed. 34 (1975) 97-108.

18. SEDIVEC, V. and FLEK, J. Exposure tests for xylenes. Int. arch. occup. environ. health 37 (1976) 219-232.

19. SEUTTER-BERLAGE, F., DORP, H. L. VAN, KOSSE, H. G. J. and HENDERSON, P. T. Urinary mercapturic acid excretion as a biological parameter of exposure to alkylating agents. Int. arch. occup. environ. health 39 (1977) 45-51.

20. STUIK, E. J. Biological response of male and female volunteers to inorganic lead. Int. Arch. Arbeitsmed. 33 (1974) 83-97.

21. THÜAUF, J., SCHALLER, K.-H., ENGELHARDT, E. and GOSSLER, $K$. Der Kadmium-Gehalt der menschlichen Placenta. Int. arch. occup. environ. health 36 (1975/76) 19.

22. VERBERK, M. M. and SALLE, H. J. A. Effects on nervous function in volunteers ingesting mevinphos for one month. Toxicol. appl. pharmacol. 42 (1977) 351-358.

23. VOS, M., BIERSTEKER, K., HARING, B., et al. Verkennend onderzoek naar de betekenis van locale verschillen in waterhardheid voor de gezondheid [Explorative study of the significance of local differences in water hardness for health]. Tijdschr. soc. geneesk. (In press)

24. WIBOWO, A. A. E., CASTILHO, P. DEL, HERBER, R. F. IM. and ZIELHUIS, R. L. Blood lead and serum iron level in nonoccupationally exposed males and females. Int. arch. occup. environ. health 39 (1977) $113-120$.

25. ZIELHUIS, R. L. Biological quality guide for inorganic lead. Int. Arch. Arbeitsmed. 32 (1974) 103-127.

26. ZIELHUIS, R. L. Die Bedeutung arbeitsmedizinisch-toxikologischer Erfahrung für die Umweltmedizin. In: Arbeitsmedizinische Probleme des Transport und Verkehrswesens; die sogenannte vinylchloridKrankheit. Bericht 14. Jahrestagung der 
Deutschen Gesellschaft für Arbeitsmedizin, Hamburg 17-19 Okt. 1974. Stuttgart, Gentner 1975, pp. 21-31.

27. ZIELHUIS, R. L. Second international workshop permissible levels for occupational exposure to inorganic lead. Int. arch. occup. environ. health 39 (1977) 59-72.

28. ZIELHUIS, R. L. Standard setting for work conditions as risky behaviour. In $P$. GRANDJEAN (ed.), Standards setting. Arbejdsmiljöfondet, Copenhagen 1977.

29. ZIELHUIS, R. L., CASTILHO, P. DEL, Levels of lead and other metals in human blood: Suggestive relationships, determining factors. In: SCIENTIFIC COMMITTEE ON METALS, PERMANENT COMMISSION, INTERNATIONAL ASSOCIATION OF OCCUPATIONAL HEALTH, Workhop interaction of metals. Stockholm 1977. (In press)

30. ZIELHUIS, R. L., STUIK, E. J., HERBER, R. F. M., SALLE, H. J. A., VERBERK, M. M., POSMA, F. D. and JAGER, J. H. Smoking habits and levels of lead and cadmium in blood in urban women. Int. arch. occup. environ. health 39 (1977) 5358. 